\title{
CONSTRUCTION OF INSTITUTIONAL IDENTITIES BY MALE INDIVIDUALS IN SUBORDINATE POSITIONS IN THE JAPANESE WORKPLACE ${ }^{1}$
}

\author{
Junko Saito
}

\begin{abstract}
This study qualitatively examines how male individuals in subordinate positions in a Japanese workplace construct institutional identities in superior-subordinate interactions in the workplace. The analysis demonstrates that the male subordinates' use of the masu form (the addressee honorific form) in conjunction with their epistemic stance contributes to the display of different facets of institutional identities. It also shows that individuals in subordinate positions draw on various discourse strategies, such as incomplete phrases and the plain form (the non-honorific form), so as to obscure the social relationships between superiors and themselves, as well as to avoid performing the role of buka 'work subordinate', who is obligated to obey superiors. Confirming the findings of previous research on identity construction, this study demonstrates that by strategically manipulating their linguistic resources, male subordinates can display different institutional identities on a moment-by-moment basis in a given context. Furthermore, the study contributes to the examination of power relations in workplace discourse, as well as touching upon a gender difference in language use.
\end{abstract}

Keywords: Workplace discourse; Identity construction; Japanese; Epistemic stance; Male subordinates; Power relations.

\section{Introduction}

Much previous research on workplace talk in business organizations (e.g., Baxter 2008; Chiles 2007; Holmes 2006; Holmes and Marra 2004; Holmes and Stubbe 2003; Sunaoshi 1994; Takano 2005; Vine 2004) has extensively explored linguistic practices of individuals in leadership positions and how such individuals construct and assert multiple social identities in workplace interactions. In contrast, very little research has focused on the discursive practices of subordinates in a workplace hierarchy. Studies on identity construction in workplace settings are no exception.

Taking the social constructionist point of view, this study empirically investigates the multi-faceted institutional identities of male individuals in subordinate positions in

1 I wish to express my sincere gratitude to an anonymous reviewer of Pragmatics for insightful and valuable comments and Laurie Durand for her thorough editorial assistance. An earlier version of this paper was presented at the $12^{\text {th }}$ International Pragmatics Conference (IPrA) in Manchester, UK. Any errors and infelicities are entirely my own. 
superior-subordinate interactions. It will contribute to the development of research on institutional talk. The research questions that this study addresses are (1) What kind of institutional identities do male individuals in subordinate positions construct when interacting with their superiors? (2) In what kind of situations are different institutional identities put forward? and (3) What linguistic resources and strategies are utilized to index these identities?

Ochs (1993: 288) considers social identity "a cover term for a range of social personae that include social status, roles, positions, relationships, and institutional and other relevant community identities one may attempt to claim or assign in the course of social life." She also articulates the idea that social identity is interactionally constructed through language use that indexes particular stances and social acts. Ochs goes on to say that a speaker's claim to a particular identity will not be ratified unless the other interlocutor understands the conventional association of the displayed stances and acts with the particular social identity. In this respect, social identity is jointly constituted by both the speaker and the interlocutor in the course of interactions. This notion is also mentioned by Zimmerman (1998: 106) who claims that "alignment of identities is an achievement." Ochs discusses both affective and epistemic stances. Of these two kinds of stance, epistemic stance plays a significant part in the analysis in this study. Ochs (1996: 410) defines epistemic stance as "knowledge or belief vis-à-vis some focus of concern, including degrees of certainty of knowledge, degrees of commitment to truth of propositions, and sources of knowledge, among other epistemic qualities." In this study, I adopt Ochs' definitions of social identity and epistemic stance, as well as her notion of the relationship between language and identity construction.

\section{Previous studies on institutional identities}

Several studies on institutional talk (e.g., Chiles 2007; Clifton and Van De Mieroop 2010; Cook 2006, 2008, 2011; Holmes 2006; Holmes and Stubbe 2003; Jacoby and Gonzales 1991; Rees and Monrouxe 2010; Sunaoshi 1994; Takano 2005; Vine 2004) provide significant evidence that different facets of social identities are put forward depending upon the sequence of interactions and situated contexts. For example, previous research on business organizations (e.g., Chiles 2007; Holmes 2006; Holmes and Stubbe 2003; Sunaoshi 1994; Takano 2005; Vine 2004) has empirically demonstrated that individuals in an institutional hierarchy enact diverse leader identities, such as the identity of an authoritative and aggressive leader and the identity of a more empathetic and solidarity-oriented leader who attempts to minimize hierarchical differences.

In the research on Japanese workplace talk, Sunaoshi (1994) and Takano (2005) illustrate how Japanese female professionals linguistically project authoritative identities. Sunaoshi (1994) points out that female superiors in her study choose to utilize linguistic resources that enable them to perform socio-culturally accepted female roles, namely those of mothers and passive females. By doing so, the female leaders attempt to maximize their institutional power in a public sphere. In the same vein, Takano (2005) argues that female professionals in managerial positions perform not only the identity of a collaborative, rapport-oriented leader, but also an authoritative role by adopting polite and deferential language. What is remarkable in Takano's study is that female leaders use polite language that is normatively characterized as female speech in 
order to project the authoritative role. Nevertheless, the previous research on institutional talk in business organizations does not explore identity construction by individuals in subordinate positions.

Empirical investigations of identity construction in institutional settings (e.g., Clifton and Van De Mieroop 2010; Cook 2006, 2008; Jacoby and Gonzales 1991; Rees and Monrouxe 2010; Vickers 2010) have demonstrated how social identities vary on a moment-by-moment basis and how individuals actively construct both their own identities and those of their interlocutors. Jacoby and Gonzales (1991), who examine the construction of expert and novice identities in a university research group, find that in some situations, expert and novice identities are manifested that fit the prescribed institutional hierarchy, while in other situations, these identities are constituted contrary to the hierarchy. Their research shows that individuals of lower status can project identities as experts; at the same time, higher status individuals can manifest identities as novices in a given interaction; this fluidity in their identities allows power relations to be reversed at times. It is based on these observations that the authors contend that "interactionally achieved identities are only candidate constitutions of Self and Other until some next interactional move either ratifies or rejects them in some way" (174). This is a useful observation for my research; when subordinates display identities as experts in a workplace, their superiors may ratify or reject their actions, and may position themselves as novices. It is the fluidity of identities that allows the expected power relationships of the workplace to be reversed in some of these interactions.

Likewise, Cook's (1996, 2006, 2008) research is insightful and helpful in analyzing how individuals attempt to frame their social relationships with other interlocutors. She proposes that the addressee honorific, which is known as the masu form, indexes a public presentational mode of self in which a speaker is in his or her "public display" mode (1996: 74). Cook $(2006,2008)$ examines academic consultation sessions between professors and students in university settings. She finds that when both professor and student speak in the masu form, they display their professional identities. In other words, 'the professor speaks as a 'professor' and the student as a "student"" (Cook 2008: 19). According to Cook (2008: 19), "the masu exchange indexes that their relationship is official and public, and not personal and private." Cook further observes students' strategic use of language, such as the use of incomplete sentences or phrases and the co-construction of utterances with professors. Because an incomplete sentence or phrase leaves out the final verb that determines the speech style of the utterance, the use of an incomplete sentence can be a useful strategy for the student to avoid choosing a particular speech style. Likewise, a student's joint construction of an utterance with a professor is a way for the student to avoid playing a subordinate role in an interaction, because it allows the student's utterances to be embedded in the professor's or vice versa. Thus, Cook points out that students' discourse strategies function to obscure their social relationship with the professor.

I also observe in my data that male subordinates employ some of the strategies that the students in Cook's $(2006,2008)$ research use. Building on Cook's studies, this study explores the construction of institutional identities by male employees in subordinate positions in a Japanese workplace. 


\section{The study}

\subsection{Research site and participants}

The research site for this study is a dental laboratory in the Tokyo metropolitan area that manufactures dentistry products, such as dentures and crowns, with 59 workers in total (49 men and 10 women). The company consists of administration and three departments: General affairs, manufacturing, and sales. The individuals in managerial positions are all male. Although the company is small, employees consider the workplace a corporation, rather than a family business.

In this study, employees who are in positions of lower status in relation to their interlocutors are considered subordinates. In this workplace, there are 13 male superiors with managerial titles. Seven male superiors originally participated in the research; however, the data from only five superiors, as shown in Table 1, will be presented in this study. Nakata occupies the lowest rank among them. Each superior has at least 40 subordinates to interact with across departments, and all except for Sato possess governmental licenses to engage in making dentistry products. Among male subordinates with whom the superiors interacted, there are four who take part in the interactions this study analyzes; they are presented in Table 2. ${ }^{2}$ Yamada and Matsuno are dental lab technicians, possessing governmental licenses. All the participants' names are pseudonyms.

Table 1: The participants in superior positions

\begin{tabular}{llccc}
\hline Name & \multicolumn{1}{c}{ Title } & Rank in the company & Department & Age \\
\hline Sasaki & President & 1 & Administration & 64 \\
Kubo & Executive Director & 2 & Administration & 49 \\
Sato & Department Chief & 5 & Sales & 45 \\
Ueda & Department Chief & 5 & Manufacturing & 46 \\
Nakata & Section Head & 8 & Manufacturing & 33 \\
\hline
\end{tabular}

Table 2: The participants in subordinate positions

\begin{tabular}{lllc}
\hline Name & Department & Age & $\begin{array}{c}\text { Years of service in the } \\
\text { company }\end{array}$ \\
\hline Kataoka & General Affairs & 24 & 2 \\
Yamada & Manufacturing & 27 & 7 \\
Inoue & Sales & 29 & 6 \\
Matsuno & Manufacturing & 31 & 7 \\
\hline
\end{tabular}

Table 3 provides a simplified organizational chart that indicates the relative positions of the participants. The superiors and subordinates who are listed in Tables 1

2 Although this workplace has10 female employees, I could not obtain enough relevant data from cross-sex interactions to include them in the analysis. For this reason, this study focuses primarily on male subordinates' linguistic practices in same-sex interactions, although I touch upon a gender difference in language use in a later section. I am aware that the imbalance in participants' gender is one of the limitations in this study. 
and 2 are in boldface. The organization of each department differs depending on its size. The sales department has a department chief and a section head, while the general affairs department has only a department chief. Neither department has a general manager. The manufacturing department consists of six sections with (in order of rank) a general manager, a department chief, three section heads, and two supervisors. Nakata and Ueda belong to different sections of the manufacturing department and engage in making different synthetic products. Nakata, Ueda, and the other section head are under the general manager's direct supervision. Ueda is ranked under the general manager and supervises another section head and a supervisor, while Nakata only superintends the other supervisor.

Table 3: The organizational chart

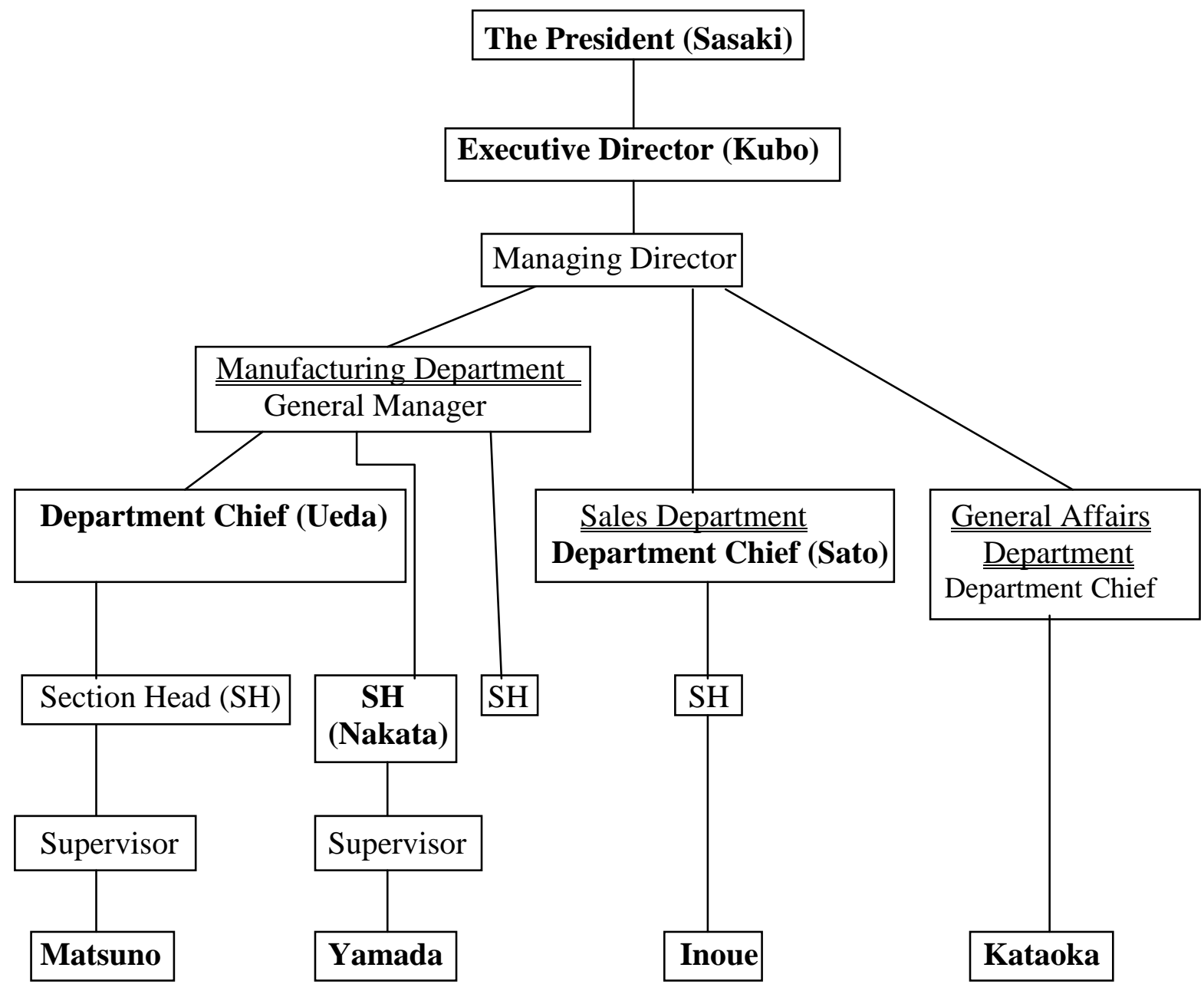




\subsection{Data}

The data for this study are elicited from more than 30 hours of recordings collected over a two-month period. With the written consent of all employees in the company, interactions between male superiors and different subordinates were audio-recorded. I participated in this company as a researcher; however, employees increasingly became comfortable with my presence. Occasionally, I was asked to help out female employees in the sales department who engage in clerical work.

Recording began about two weeks after employees seemed accustomed to my presence. The data were originally collected for a different research purpose. The participants in superior positions were asked to carry voice recorders around with them and audio-record face-to-face interactions with their subordinates. It was agreed that I would turn on each of their recorders once each day, and then the superiors would let them play until they automatically turned off. Since the recording started the moment voice-recorders were given to the superiors in the morning and continued until they automatically stopped, the superiors did not have to turn on the recorders every time they interacted with their subordinates. This process possibly also worked to minimize superiors' instinct to control which conversations were recorded. Thus, "the observer's paradox" was presumably minimized, and recorded interactions were very close to naturally occurring conversations.

I was not present on the spot during recording; however, I carried out participant observation to observe what was happening during recording and to collect ethnographic information relevant to data analysis. Due to this methodological procedure, the superiors were aware when their conversations were recorded; in contrast, the subordinates who are the focus in this study did not even know when they were being recorded.

\subsection{General linguistic practices in the workplace}

Although the company is small, its social structure emphasizes hierarchical differences. All subordinates address their superiors by titles or their last names with the suffix san, which can be translated as Mr., Miss, Ms., or Mrs., and predominantly employ the masu form (the addressee honorific form) when interacting with their superiors. Superiors largely address male subordinates by their last names with or without the suffix kun, which is loosely translatable as Mr. when addressed to a subordinate, and female subordinates by their last names with the suffix san. Superiors primarily use the plain form, which is the non-honorific form, when interacting with their subordinates.

\section{Definition of the linguistic forms}

Japanese has two morphological verbal forms: The masu form (the addressee honorific form) and the plain form (the non-honorific form). A speaker of Japanese generally must choose one of these forms in a clause-final position when producing an utterance.

In this study, the plain form includes the plain form of verbs/i-type adjectives, the copula $d a$, nouns/na-type adjectives with the deletion of the copula $d a$, the informal directive form Verb-te, the tag-like form jan 'isn't it?', and the informal/casual reactive 
token un 'yeah'. The masu form includes the masu form of verbs, the copula desu, and formal reactive tokens $h a i$ 'yes' and $h a$ 'yes'. Table 4 lists the forms included in each category for this study, and Table 5 gives examples.

Table 4: The masu and plain forms

\begin{tabular}{l|l}
\hline \multicolumn{1}{c|}{ Masu form } & \multicolumn{1}{c}{ Plain form } \\
\hline (1) Masu form of verbs & (1) Plain form of verbs/i-type adjectives \\
(2) The copula desu & $\begin{array}{l}\text { (2) The copula da } \\
\text { (3) Nouns/na-type adjectives with the deletion of the copula } d a\end{array}$ \\
(3) Formal reactive tokens: & $\begin{array}{l}\text { (4) Verb-te } \\
\text { hai 'yes'/ha 'yes' }\end{array}$ \\
& $\begin{array}{l}\text { (5) jan 'isn't it?' } \\
\text { (6) Casual/informal reactive token: } u n \text { 'yeah' }\end{array}$ \\
\hline
\end{tabular}

Table 5: Examples of the masu form and the plain form

\begin{tabular}{|c|c|c|}
\hline & Masu form & Plain form \\
\hline Verbal form & $\begin{array}{l}\text { yuki ga futteimasu } \\
\text { (It's snowing) }\end{array}$ & $\begin{array}{l}\text { yuki ga futteiru } \\
\text { (It's snowing) }\end{array}$ \\
\hline$i$-type adjectival form & oishii desu (It's delicious) & oishii (It's delicious) \\
\hline The copula desu/da & $\begin{array}{l}\text { kirei desu (It's beautiful) } \\
\text { ame desu (It's raining) }\end{array}$ & $\begin{array}{l}\text { kirei da (It's beautiful) } \\
\text { ame da (It's raining) }\end{array}$ \\
\hline Noun without the copula $d a$ & & ame (It's raining) \\
\hline $\begin{array}{l}N a \text {-type adjectives } \\
\quad \text { without the copula } d a\end{array}$ & & kirei (It's beautiful) \\
\hline Verb-te & & tabete (Eat!) \\
\hline$\overline{\text { Jan }}$ & & $\begin{array}{l}\text { oishii jan } \\
\text { (It's delicious, isn't it?) }\end{array}$ \\
\hline
\end{tabular}

Note. The targeted forms appear in boldface. 


\section{Analysis}

The six excerpts that I analyze were selected for two main reasons. First, the linguistic phenomena that I focus on here are observed across departments; thus, they clearly represent male subordinates' linguistic practices in this workplace. Second, these excerpts provide enough examples of these linguistic phenomena to answer the research questions for this study; they display how male subordinates put forward different identities in the course of interactions and how the subordinates utilize linguistic resources and strategies to index these identities. The analysis demonstrates that in inter-status interactions, male subordinates' use of the masu form in conjunction with their epistemic stance contributes to the display of different facets of their institutional identities; depending on their degree of certainty or knowledge about the topic in question, male subordinates put forward different institutional identities.

\subsection{The construction of buka 'work subordinate' identity}

In interactions between superiors and subordinates, downward talk from superiors to subordinates is predominant. Most of the talk time is occupied by superiors; subordinates give responses when appropriate. Hence, male subordinates' utterances are primarily reactive tokens, such as acknowledgement and confirmation, in the masu form. On these occasions, male subordinates simply act as buka 'work subordinates', who are obligated to obey superiors. Excerpt (1) shows such an instance. In all of the excerpts, subordinates' use of the masu form is in boldface and their use of the plain form is double-underlined.

(1) [Sasaki is the company president; Kataoka is a non-titled employee from the general affairs department.]

1 Sasaki: $\quad$ kataoka-kun warui kedo, shita e itte mite,

$2 \rightarrow$ Kataoka: hai.

'Mr. Kataoka, I am sorry, but go downstairs, and'

yes-Pol

3 Sasaki: ee-eegyoo nippoo no ni juu ichi nichi bun ga dokka

$\begin{array}{lllc}\text { ee-eegyoo nippoo no ni juu ichi nichi bun } & \text { ga } & \text { dokka } \\ \text { sales daily report of twenty one date for } & \text { SB } & \text { somewhere }\end{array}$

$4 \quad$ ni aru ka nanka mite kite kureru $\uparrow$

in exist Q or not see come-give

'Would you check if there is the daily sales report for the 21 st somewhere [downstairs]?'

$5 \rightarrow$ Kataoka: eegyoo nippoo [desu $k a \uparrow$

sales daily report Cop-Pol Q

'The daily sales report, is it what you are asking for?'

6 Sasaki:

[un.

yeah

'Yeah.'

In line 1, Sasaki identifies Kataoka as his buka by addressing him with the suffix 
kun 'Mr.', and in lines 3-4, he makes a request to Kataoka to find the daily sales report for the 21st somewhere downstairs. In response to Sasaki, Kataoka politely provides an acknowledgement token in line 2 and a confirmation question, which indicates his uncertainty and his stance of wanting to precisely perform Sasaki's request, in line 5. By doing so, Kataoka projects an identity as a buka 'work subordinate' who simply obeys Sasaki's directive.

\subsection{The construction of professional identity}

My data also show that in superior-subordinate interactions, male subordinates construct professional identities in addition to the identity of buka 'work subordinate'. Consider excerpt (2). During this exchange, Nakata (a superior) examines a synthetic replacement that Yamada (a subordinate) manufactured. Both Nakata and Yamada are dental lab technicians, manufacturing synthetic products.

(2) [Nakata is a section head from the manufacturing department; Yamada is a non-titled employee from the manufacturing department.]

\begin{tabular}{|c|c|c|}
\hline 1 & Nakata: & kara: kono rain \\
\hline & & The shape of the synthetic replacement TP good \\
\hline \multirow[t]{3}{*}{2} & & $o \quad$ moo sukoshi $[($ kinshin $\quad$ yori $)$ \\
\hline & & OB more a bit tooth surface toward \\
\hline & & $\begin{array}{l}\text { 'The shape of the synthetic replacement is good; so, this line [should be] } \\
\text { a little bit directed toward the area closer to the central teeth.' }\end{array}$ \\
\hline \multirow[t]{2}{*}{3} & $\rightarrow$ Yamada: & 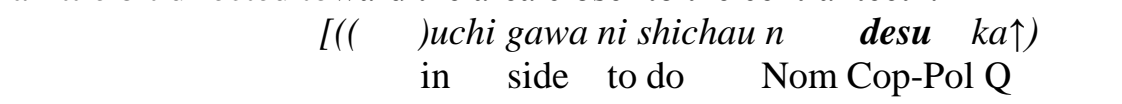 \\
\hline & & '( ） bring it (the line) inward?' \\
\hline 4 & Nakata: & $\begin{array}{l}\text { uchi gawa ni shite. } \\
\text { in side to do }\end{array}$ \\
\hline 5 & $\rightarrow$ Yamada: & $\begin{array}{l}\text { 'Shift it inward.' } \\
\text { chicchaku nacchaimasu yo. } \\
\text { smaller become-Pol IP }\end{array}$ \\
\hline \multirow[t]{2}{*}{6} & Nakata: & $\begin{array}{l}\text { 'It (the replacement) will be smaller.' } \\
\text { naranai. ima de chotto dekaku mieru kara. } \\
\text { become-Neg now a bit big look because }\end{array}$ \\
\hline & & 'It won't. Because it looks a little bit big now.' \\
\hline \multirow[t]{2}{*}{7} & Yamada: & $\begin{array}{l}a \because: \\
\mathrm{SF}\end{array}$ \\
\hline & & $\begin{array}{l}\text { 'Oh::' } \\
\text { dakara chott-moo choi (20) sono (4.0) kono rain ourai ka-na }\end{array}$ \\
\hline \multirow{2}{*}{8} & Nakata: & $\begin{array}{l}\text { dakara chott- moo chou (2.0) sono (4.0) kono rain gural ka-na. } \\
\text { thus a bit more a bit } \quad \text { SF this line about IP }\end{array}$ \\
\hline & & 'That's why a bit, a bit more (2.0) well (4.0) about this line, I wonder.' \\
\hline 10 & $(5.0)$ & \\
\hline 10 & $\rightarrow$ Yamada: & $\begin{array}{l}\text { hai. } \\
\text { hai. } \\
\text { yes-Pol yes-Pol } \\
\text { 'Alright. Alright.' }\end{array}$ \\
\hline
\end{tabular}

In line 3, Yamada preempts what Nakata is going to say and asks a confirmation question regarding Nakata's probable but yet unspoken directive. Here, Yamada acts as a buka 'work subordinate' who seeks Nakata's direction. In line 4, Nakata addresses a 
directive to Yamada. Then in line 5, by using the masu form and the particle yo, Yamada challenges Nakata's order. Morita (2002) contends that the particle yo, an epistemic stance marker, expresses the speaker's strong authoritative stance toward the utterance. Yamada's use of this particle functions as an indicator of his certainty about the consequence of Nakata's directive. As mentioned previously, Cook (1996) proposes that the masu form indexes a speaker's public presentational stance. At this point of the interactional sequence, the combination of the masu form and the particle yo contributes to Yamada's construction of an institutional identity as a full-fledged professional dental technician who issues an opposing comment. In line 6, Nakata strongly refuses to ratify Yamada's display of expertise and gives a justification for his directive delivered in line 4. Upon Yamada's acknowledgement token in line 7, Nakata reissues the directive in line 8 . In line 10, Yamada shifts his identity back to buka 'work subordinate' and simply accepts Nakata's directive.

Excerpt (2) shows that a subordinate's use of epistemic stance markers (a confirmation question and the particle yo) along with his use of the masu form works to construct different institutional identities; a confirmation question contributes to display an identity of buka 'work subordinate', while the particle yo projects a professional identity. This excerpt also provides evidence that a subordinate's social identity shifts on a moment-by-moment basis in a given interaction. Moreover, this excerpt illustrates how a superior's ratification plays a part in the construction of the subordinate's identity, because Yamada shifts his identity from professional dental technician to buka 'work subordinate' after Nakata's rejection of ratification in line 6 .

\subsection{The use of linguistic strategies to obscure the institutional hierarchy}

The next excerpt is another example of a male subordinate constructing a professional identity with the use of the masu form and the particle yo. What is remarkable in this excerpt is that, just as the students do in Cook's $(2006,2008)$ study, the male subordinate here employs an incomplete sentence in order to obscure the hierarchical relationship between the superior and himself.

In excerpt (3), Sasaki (the company president) initiates a conversation with Kataoka (a non-titled employee from the general affairs department) to make a suggestion about schedule management. Kataoka accounts for what the general affairs department is currently doing, which triggers negotiation between Sasaki and himself.

1 Sasaki: yotee hyoo o ne^kaku chiifuni oitoite, yotee o kakinasai tte schedule chart OB IP each chief to place schedule OB write QT yutte, de agete kureba, getsuyoo nara getsuyoobi ni are sureba, sono say and collect give-if Monday if Monday on that do-if that

shuu no are ga wakarujan. week of that SB know Tag

'If you give each chief a schedule chart, tell him to write a schedule, and collect it, if it's on Monday, if you do so on Monday, you will grasp that [schedule] in that week, right?'

4 Kataoka: ima marumori kachoo ga toriaezu minna no kiite, now Marumori dept.chief SB for the time being everyone of ask 
5 Sasaki: $\quad$ un.

'Currently, department chief Marumori asks everyone about [their schedule] for the time being, and'

uh huh

'Uh huh'

6 Kataoka: sore o shuu no getsuyoobi ni

that $\mathrm{OB}$ week of Monday on

'that [their schedule] on Monday'

7 Sasaki:

un. $u:: n$.

uh huh uh huh

'Uh huh Uh hu::h.'

8 Kataoka: kakidashite,

write out

'Write out [their schedule on Monday].'

9 Sasaki: $\quad u:: n$.

uh huh

'Uh huh'

$10 \rightarrow$ Kataoka: tte yиu no de yatterun desu yo.

QT say Nom by do-Prog Nom Cop-Pol IP

'[Currently, department chief Marumori] is doing this by [asking everyone about their schedule and writing it out on Monday].'

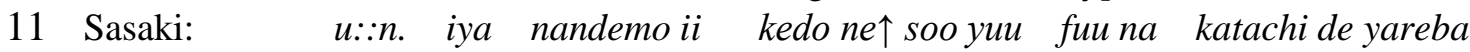
uh huh no anything good but IP that like style form by do-if

12 sa::un.

IP yeah

'Uh huh. Well, anything is okay but, if you do it that way [i.e. giving each chief a schedule chart and collecting it on Monday], yeah.

$13 \rightarrow$ Kataoka: sonna yarikata mo aru to.

such way too exist QT

'There also exists such a way.'

14 Sasaki: aru to.

exist QT

'It does.'

In lines 1-3, Sasaki makes a suggestion to Kataoka regarding schedule management. In response to Sasaki, Kataoka explains what they currently do in the general affairs department in lines 4-10. Notice that Kataoka ends his utterance in the masu form and the particle yo (line 10). The combination of these linguistic features displays his authoritative stance and projects his professional identity as a member of the general affairs department who is more knowledgeable about the topic in question than Sasaki is. Subsequently, Sasaki accepts what the general affairs department is doing, yet justifies his original suggestion. It is noteworthy that in line 13, Kataoka delivers his utterance, acknowledging Sasaki's suggestion in an incomplete sentence. As Cook $(2006,2008)$ points out, an incomplete sentence does not mark a particular speech style, and hence makes the relationships between interlocutors obscure. Just like the students in Cook's studies, Kataoka uses an incomplete sentence at this point as a strategy to make the hierarchical relationship between Sasaki and himself ambiguous. By doing so, Kataoka avoids defining his relationship with Sasaki and further projects an identity other than that of buka 'work subordinate'. Subsequently, Sasaki aligns with Kataoka by repeating part of Kataoka's utterance. Here, unlike in excerpt (2), the 
superior ratifies the subordinate's display of his professional identity.

Likewise, excerpt (4) illustrates that a male subordinate uses the masu form and the particle yo to enact his professional identity, as well as incomplete phrases to obscure a hierarchical relationship with a superior. Prior to this segment, Kubo (the executive director) and Nakata (a section head from the manufacturing department) are discussing a problematic synthetic tooth.

1 Kubo: nyuutoo no tokoro ni butsukaranai gurai dattara interdental papilla of place to bump-Neg to the extent Cop-if chotto (kakete) ii tte. a little chip good QT

'[The dentist] says that it is okay to chip [the synthetic tooth] a bit if it does not bump against the interdental papilla.'

$3 \rightarrow$ Nakata: demo moo kocchi ga kondo: but already this side SB then 'But, then, this side already'

4 Kubo: $u:: n$. chotto ima (keesoku shite). konpyuutaa de. SF a little now calculation do computer by 'We::ll, now (calculate [it]) a little bit by computer.'

$5 \rightarrow$ Nakata: iya:: demo sore yori zuibun nagaku nacchaimasu yo. kore. no but that than considerably long become-Pol IP this 'Well::, but this will become considerably longer than that (the actual synthetic tooth).'

6 Kubo: u::n. maa kihon teki ni wa kore koo nareba ii $n$ da.

$7 \quad$ (tsume) ga.

SF SF basically TP this like become-if good Nom Cop

end $S B$

'We::1l, it should be basically okay in the end if this becomes like this.'

$8 \rightarrow$ Nakata: ha:: iya kyuushi kyuushi ga.

yes-Pol no molar tooth molar tooth SB

'Ye::s. No, a molar tooth, [I am saying that] a molar tooth [will become considerably longer].'

9 Kubo:

kore un.

this yeah

'This. Yeah.'

In lines 1-2, Kubo explains what the dentist's instructions were. In line 3, Nakata uses an incomplete phrase to assess what Kubo has just said. With the incomplete phrase, Nakata avoids defining a hierarchical relationship with Kubo and simultaneously shows that he is not enacting a role as Kubo's buka 'work subordinate'; nevertheless, Kubo constructs institutional hierarchy in line 4 by issuing a directive to Nakata. Then in line 5, Nakata counters Kubo by predicting the outcome of Kubo's directive in the masu form with the particle yo. Here, Nakata projects his institutional identity as a full-fledged dental technician, although his display of expertise is not completely ratified by Kubo in lines 6-7. Kubo's rejection of Nakata's attempt to present his professional identity triggers Nakata to shift his identity to buka 'work subordinate' in line 8. A moment after his identity shift, Nakata changes his stance and contests Kubo 
in an incomplete phrase, which again avoids identifying the social relationship between Kubo and himself.

Excerpt (5) demonstrates that a male subordinate co-constructs an utterance with a superior and uses the plain form so as to make the institutional hierarchy equivocal. This exchange takes place in the sales department. After returning from a particular dental clinic, Inoue (a non-titled employee) brings up a problematic issue to Sato (the sales department chief).

1 Inoue: takeyama-sensee ichi nen mae no keesu na n desu kedo, jii enu ga

$2 \rightarrow$ mapputatsu ni warete, tsukurinaoshinan desu yo:

exactly two in split remake Nom Cop-Pol IP

'As for Dr. Takeyama's case that we dealt with a year ago, the GN

(name of the synthetic product) is split in two and needs to be re-manufactured.'

3 Sato: un.

uh huh

'Uh huh.'

$4 \rightarrow$ Inoue: san wari biki gurai de ii desu ka ne^

three percentage discount about Cop good Cop-Pol Q IP

'About 30 percent discount is good enough, do you agree with it?'

5 Sato: de mo ii shi, ano doo yuu jootai de, ware-koopingu kara

Cop also good SF what situation under spli- coping from

6

wareten $=$

split-Prog

'That's also fine. Well, under what situation, it is split, from the coping

(the cap covering a tooth)'

7 Inoue: =koopingu kara.

coping from

'From the coping.'

8 Sato: $\quad$ wareten $n o \uparrow$

split-Prog Nom

'[Is it] split [from the coping]?'

$9 \rightarrow$ Inoue: $\quad$ roku ban mapputatsu.

six number exactly two

'Number six [is split in] two.'

10 Sato:

soshitara nakata ni kiite sa, ano nani (

) dai dake de ii $\quad k a$

then Nakata to ask IP SF what fee only Cop good Q

11

dooka kiite mireba ii jan.

whether ask try-if good Tag

'Then, you should ask Nakata, well, whether only ( ) fee is good enough or not, right?'

In lines 1-2, Inoue reports a situation that has happened at Dr. Takeyama's clinic to Sato. Here, he projects himself as a professional salesperson with the use of the masu form and the particle yo. In the next turn, Sato ratifies Inoue's professional identity by giving an acknowledgement token. In line 4, Inoue proposes a discount rate and solicits agreement with the use of the particle $n e$. Morita (2002: 226) claims that $n e$ indicates an 
epistemic stance, indexing "a stance of weak or incomplete authority in relation to" the addressee. Thus, Inoue's use of ne marks his limited authority on the discount rate that he can offer to the dentist. Here, Inoue, as a "professional" salesperson, is negotiating the discount rate with Sato, and in the next turn, Sato accepts his proposal. What is also noticeable is that in line 7, Inoue delivers an incomplete phrase by latching onto Sato's prior utterance. In the next turn, Sato continues what is interjected by Inoue and finishes his utterance. As a result, Inoue's utterance in line 7 is embedded in Sato's utterance, and in lines 5-8, Inoue and Sato jointly construct the question in the plain form: doo уии jootai de, koopingu kara wareten no $\uparrow$ 'under what situation, is it split from the coping?' It is also worth noting that in line 9, Inoue provides a response in the plain form. Cook (2008) contends that the reciprocal use of the masu form indicates that the relationship is official and not personal and private, implying that the mutual exchange of the plain form marks a private and personal relationship. Here, Inoue transforms the interaction with Sato into small talk in which two colleagues privately discuss the matter in question. In addition, Cook (2006) argues that the co-construction of an utterance between individuals of different status renders the hierarchical relationship obscure. Inoue's use of the plain form at this point further strengthens the relational ambiguity. In lines 10-11, Sato responds to Inoue by giving a suggestion, which indicates his ratification of the hierarchical vagueness that has interactionally been created up to this point.

Male subordinates' use of incomplete sentences or phrases, their use of the plain form, and their joint construction of an utterance with a superior function as strategies to obscure the institutional hierarchy and project a social identity different from buka 'work subordinate'.

Excerpt (6) occurs in the manufacturing department. A superior initiates a conversation by giving directives regarding a denture to a male subordinate.

(6) [Ueda is the manufacturing department chief; Matsuno is a non-titled employee from the manufacturing department.]

1 Ueda: $\quad$ kore: saki ni kore hairetsu shite. ato de kore pureeto tsukuru kara. these first at these align do later these frame make because 'First, align these [synthetic teeth], because I will make a frame for these.'

$2 \rightarrow$ Matsuno:

"hai. ${ }^{\circ}$

yes-Pol

'Yes.'

3 Ueda:

un. ja kore chotto ( yeah. then these a little shinai to. de kore jinkoo shi mo moratta $n$ da kedo, do-Neg if and these artificial teeth also received Nom Cop but karini kore narabetoite. temporarily these align 'Yeah. Well, if you do not align these, I do not know ( ) a little bit. And I have also received these artificial teeth, so, align these temporarily.'

$6 \rightarrow$ Matsuno:

ha. ${ }^{\circ}$

yes-Pol

'Yes.'

7 Ueda:

de ato de kore ( and later these
). chitan tsukutte, hairetsu shiteki datta $n$ titanium make align trial Cop Nom


8

9 Matsuno:

$10 \rightarrow$

11 Ueda:

12 Matsuno:

$13 \rightarrow$

14 Ueda:

$15 \rightarrow$ Matsuno:

16 Ueda:

19 Ueda:

$20 \rightarrow$ Matsuno:

21 Ueda:

$23 \rightarrow$

24 Ueda:
22 Matsuno:

da kedo, kore chotto gyaku ni shichau kara.

Cop but, these a little reverse in do because

'And later ( ) these. At first, I was supposed to make [a frame] of titanium and align [the teeth on the frame] experimentally, but I will reverse [the manufacturing order].'

wai yuu burendo oo tsu san ten go yon ten yon dakara, $\mathrm{Y} \mathrm{U}$ blend $\mathrm{O}$ two three point five four point four Cop because are janaidesu $k a \uparrow=$

that Cop-Neg-Pol Q

'Since [the teeth are made out of] YUBlendO2 (name of the material for the synthetic teeth), [thickness of the denture is] 3.5, 4. 4, isn't that the case?'

$=$ kari $n i \quad n a i \uparrow$ temporarily exist-Neg

'You have none (the materials) for temporary [alignment]?'

u::n. karini naraberu no mo chanto narabetoita hoo ga SF temporarily align Nom even properly align way SB

[ii desu yo. good Cop-Pol IP

'We::ll, even if [the synthetic teeth are] aligned temporarily, they should be aligned properly.'

[un.

yeah

'Yeah.'

saigo ni kawacchau kara.

last at change because

'because [the alignment] will change in the end.'

un.

yeah

'Yeah.'

$17 \rightarrow$ Matsuno: hoka no yatsu yatteru to. to naru to, kyoo tanonde hayaku te other of parts do-Prog when QT become it today order early at ashita gurai todokun de, tomorrow around deliver Nom Cop

'When you do other parts. Then, even if I order [the materials] today, [they] will be delivered tomorrow or so at the earliest, so'

[un.

uh huh

'Uh huh.'

[sono ato chotto ichi nichi zurechau kamoshirenai. nittee ga. that after a bit one day postpone may schedule SB.

'After that, the schedule may be postponed one day.'

un. [sore de ii.

yeah that Cop good

'Yeah. That's fine [with me].'

[koko ga. koko ga. doyoobi ga chotto dakara, oshichau here SB here SB Saturday SB a bit therefore push back

kamoshirenai.

may

'Here, here. I mean, Saturday [schedule] may be pushed back a bit.' un. 


\author{
uh huh \\ 'Uh huh.' \\ $25 \rightarrow$ Matsuno: $\quad$ koko ga ichi nichi hecchau kamoshirenai. daijoobu desu $\quad k a \uparrow$ \\ here SB one day reduce may alright Cop-Pol Q \\ 'It may become one day short here. Is it alright?' \\ 26 Ueda: un. juи go juи nana de ii. \\ yeah fifteen seventeen Cop good \\ 'Yeah. The fifteenth and the seventeenth are fine [with me].'
}

In lines $1-5$, Ueda issues directives to Matsuno, and Matsuno simply accepts them. In line 10, after checking the materials used for the denture, Matsuno addresses a negative question in the masu form, are ja nai desu ka $\uparrow$ 'Isn't that the case?' to inform Ueda of something about the denture in question. This utterance indexes Matsuno's knowledge about a denture that is made from a particular material; hence, it indicates his epistemic stance. At this point, Matsuno displays his professional identity. Then in lines 12-13, Matsuno makes a suggestion to Ueda. Vine (2004) claims that when lower status individuals give advice to higher status people, they tend to have a different type of authority that relates to their skills and expertise. Here, Matsuno further displays an identity as a dental technician and strengthens this professional identity by employing the particle yo. Furthermore, Matsuno uses incomplete phrases saigo ni kawacchau kara 'because [the alignment] will change in the end' in line 15 and hoka no yatsu yatteru to 'when you do other parts' in line 17. What is also noticeable is that in lines 20,23, and 25, Matsuno employs the plain form of the modal auxiliary kamoshirenai 'may'. Modal auxiliaries express a speaker's epistemic stance (Fukuda 2006). In addition, Makino (2002) articulates the claim that formal-to-informal shifting marks the speaker's convictions. At these points, Matsuno indicates his conviction about the schedule change. The reciprocal exchange of the plain form by Matsuno and Ueda in lines 20-25 looks as if two colleagues were privately negotiating their institutional task. Here again, Matsuno's use of both the incomplete phrases and the plain forms obscures the status difference between Ueda and himself so as to manifest his identity as other than that of a buka 'work subordinate'. Then in line 25, shifting his speech style from the plain form to the masu form, Matsuno solicits Ueda's approval. At this point, Matsuno shifts his social identity back to that of a buka 'work subordinate' who seeks his superior's approval.

\title{
6. Discussion
}

Excerpts (1) through (6) demonstrate that the male subordinates in this study discursively construct multiple institutional identities in ongoing interactions between themselves and male superiors. Linguistic resources, including the masu form and those that index epistemic stance, such as particles and questions, play an important part in male subordinates' portrayal of a different side of their institutional identities. When they give reactive tokens, such as acknowledgement and confirmation questions, to superiors (excerpts [1] and [2]) or when they seek superiors' approval (excerpt [6]), the subordinates simply project themselves as buka 'work subordinates' who are obliged to obey superiors. However, in other situations, such as when giving their superiors explanations and notifications (excerpts [3] and [5]), making suggestions to and negotiating with their superiors (excerpts [5] and [6]), and confronting their superiors 
(excerpts [2] and [4]), male subordinates put forward their professional identities over the buka identity. The excerpts also illustrate that by shifting their stance, subordinates momentarily change their institutional identities even within a single interaction. Moreover, this study provides evidence that male subordinates strategically draw on incomplete phrases and sentences, jointly constructed sentences, and the plain form so as to refrain from defining their social relationships with superiors, as well as to avoid performing a role of buka 'work subordinates'. In short, linguistic resources, subordinates' strategic use of language, and interactional contexts all contribute to male subordinates' display of different facets of their identities.

The excerpts also illustrate how male subordinates' institutional identities are actively constructed by both superiors and subordinates. Superiors ratify and reject subordinates" "interactionally achieved identity" (Jacoby and Gonzales 1991: 174) in various ways. They identify themselves as jooshi 'work superiors' and the subordinates as buka 'work subordinate' by issuing directives and assessments or by addressing subordinates with the suffix that is often used to a male individual of lower status. In addition, superiors often ratify male subordinates' professional identity by aligning themselves with the subordinates and delivering reactive tokens, or they do not ratify subordinates' expertise and instead engage in confrontations with subordinates. Hence, these excerpts clearly support Ochs" (1993: 291) claim that "social identity as a social construct is both inferred and interactionally achieved through displays and ratifications of acts and stances."

Furthermore, the excerpts in this study contribute to the examination of power relations. As several scholars (e.g., Holmes and Stubbe 2003; Mullany 2007; Thomas 1995; see also Mills and Mullany 2011) point out, social or institutional status is not the sole factor that identifies power and authority. Clearly, when male subordinates in this study play a role as buka 'work subordinate', superiors have "legitimate power"3 over those subordinates (Spencer-Oatey 2000: 33). However, there are some occasions where the prescribed institutional power relations, in which individuals in superior positions exert power over lower status individuals, do not work. When male subordinates foreground professional identity, their "expert power" 4 comes into operation (Spencer-Oatey 2000: 33). Under this circumstance, the subordinates in this study, as the authority on the topic in question, have the power to contest, make a suggestion to, and report their decisions to superiors. Even if superiors and subordinates are part of an institutional hierarchy, the male subordinates are, after all, specialists in their own work. Hence, this study illustrates that power in the workplace is not given a priori; rather, it is socially constructed and dynamically manifested on an ongoing basis in a given interaction. Even individuals in institutionally subordinate positions can empower themselves depending on situated contexts in interactions.

It should also be noted that workplace cultures differ from workplace to workplace (e.g., Holmes and Marra 2002; Schnurr 2009). Because I only examine male-to-male interactions in a particular workplace in this study, the generalizability of the outcomes of this study is limited. What I have observed in my data set may not be relevant in subordinates' linguistic practices in other institutions. In addition, I cannot apply what I

${ }^{3}$ Spencer-Oatey (2000) discusses the idea that legitimate power is the power with which an individual has the right to prescribe or demand certain things by reason of specific factors, such as social role or status.

4 According to Spencer-Oatey (2000), in expert power, an individual has some special knowledge or expertise that the interlocutor wants or needs. 
have found in this study to linguistic phenomena in cross-sex interactions in this workplace. Although I have observed similar linguistic practices among female subordinates in this company, most of these instances involve "Office Ladies" $(\mathrm{OL})^{5}$ in the sales department. OLs, who engage in clerical work, primarily work as assistants of male employees; they generally have no opportunity to be promoted to managerial positions. On the other hand, female dental lab technicians, having their own expertise, engage in the same tasks (manufacturing synthetic products) as their male counterparts do, and they could be promoted to managerial positions. Thus, OLs and female lab technicians are on different career paths, and female dental lab technicians in the manufacturing department may adopt different linguistic resources and strategies in their identity constructions, especially of their "professional" identities. Within the limited analysis of female subordinates' linguistic practices possible with the data, I have noticed a single gender difference in language use between male subordinates and OLs. Unlike male subordinates who use the particle yo, OLs have a tendency to employ the particle yo-ne when projecting their professional identities. Morita (2002: 229) maintains that yo-ne, which stands between the particles yo and ne in terms of the degree of authority, signifies that the speaker can independently assert his or her opinion; nevertheless, he or she needs an uptake from the interlocutor, "possibly as a politeness strategy." Since polite speech is ideologically associated with femininity (Okamoto 2004; Okamoto and Shibamoto Smith 2008), OLs in this workplace may utilize the particle yo-ne in order to mitigate their assertion and to display their feminine side. Although this is a different strategy than those used by male subordinates in this workplace, this may be a way for an OL to assert a professional identity. Sunaoshi (1994) argues that female leaders in her study empower themselves by using linguistic resources that project traditional female roles. The female professionals in Takano's (2005) study employ polite language so as to project an authoritative role. It may be that the OL in Excerpt (7) uses the particle yo-ne in order to maximize her power and project her authority on the matter in question.

Excerpt (7) shows an OL's use of yo-ne. In this excerpt, Watabe (an OL in the sales department), who works as an assistant of male employees in the sales department, particularly of Sato (the department chief), initiates a conversation with Sato by asking for a confirmation of a judgment she is making.

(7) [Sato is the department chief from the sales department; Watabe is a non-titled female employee from the same department.]

$1 \rightarrow$ Watabe: $\quad$ kachoo, ootake-san no keesu wa mada oitokimasu yo-ne $\uparrow$ ano

2 Dept. chief Otake Dr. of case TP still keep IP SF kinoo kita. yesterday came 'Department chief, we will still keep Dr. Otake's product, right? Well, [the one that] came yesterday.'

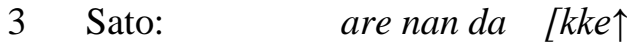
SF what Cop IP

'Well, what was it?'

$4 \rightarrow$ Watabe:

[toppu daun no yatsu.

5 Ogasawara (1998: 27) defines an OL as "a woman working regularly in an office who engages in simple, repetitive, clerical work without any expert knowledge or management responsibility." 
5 Sato:

6 Watabe:

7 Sato:

$8 \quad(2.0)$

$9 \rightarrow$ Watabe:

10 Sato:

11 Watabe:

12 Sato:

$13 \rightarrow$ Watabe: top down of thing

'A top-down thing'

chigau. chigau. nan nichi ni natteru different different what day to become

'No, No, what day [are we supposed to send]?

$\underline{\underline{e}} \uparrow$

'What?'

nan nichi ni natteru $\uparrow$

what day to become

'What day [are we supposed to send]?'

ano:: kinoo kyoo chooree de mo itte

SF yesterday today assembly in also say

'Well::, yesterday and today [you] also said in the assembly.'

un. hinichi:: wa个

uh huh date TP

'Yeah, date is?'

hinichi wa kocchi kara: [( )

date TP this from

'The date is [supposed to be ( ) ] from us.'

[hatanaka kitara, denwa shite kureru^

hatanaka come-when call do-give

'When Hatanaka (a male salesperson) comes

back, will you call [Dr. Otake] for me?'

hai.

yes-Pol

'Alright.'

In line 1 , by using yo-ne, Watabe delivers her utterance not only as assertion of her understanding of Dr. Otake's case, but also as her solicitation of affirmation from Sato about her assertion. That is, Watabe as a "professional" OL asserts her judgment that they will keep Dr. Otake's product for a while; simultaneously, she asks for Sato's confirmation about her judgment so as to be polite to Sato and possibly to display her authoritative role. Then, Watabe immediately shifts her speech style from the masu form to the plain form in line 2: ano kinoo kita 'Well, [the one that] came yesterday', which obscures the status difference between Sato and herself. Watabe further utilizes the plain form in line 4 and an incomplete phrase in line 9; her linguistic practices at these points further obscure the asymmetrical relationship between Sato and herself. In line 13, shifting her speech style back to the masu form, Watabe complies with Sato's request. Here, she manifests her identity as Sato's buka 'work subordinate'. What is noticeable in this exchange is that in the course of this interaction, Watabe foregrounds different institutional identities on a moment-by-moment basis, and Sato ratifies her display of such identities.

Excerpt (7) provides evidence that although the specific way they project their professional identities may be different, OLs in this workplace, like the male subordinates, employ the plain form and incomplete phrases, obscuring hierarchical differences between superiors and themselves. However, as I pointed out previously, female dental lab technicians, who have expert knowledge, may present their identities in a different fashion than OLs do. This certainly suggests the need for further research 
on this topic to obtain more data of male-to-female interactions from this community of practice and to scrutinize female subordinates' linguistic practices, in particular those of female lab technicians'.

\section{Conclusion}

Building on the previous research on identity construction and expanding the study of workplace talk, this study sheds light on identity construction by male subordinates in superior-subordinate interactions in a workplace. It shows how male subordinates' different institutional identities are, as interactions unfold, manifested through their use of the masu form (the addressee honorific form) along with their epistemic stances and their strategic use of language, and how these identities are interactionally achieved on a moment-by-moment basis. Furthermore, this study demonstrates that institutional power is not necessarily constrained by institutional hierarchy, but is dynamically manifested in a given context regardless of interlocutors' hierarchical rank. In other words, work subordinates can exert power over their superiors in situated contexts. The study also touches upon an intriguing gender difference in subordinates' identity construction, which calls for further data collection that would allow greater depth and breadth in the analysis.

Antaki and Widdicombe (1998: 2) contend that "people [do not] passively or latently have this or that identity which then causes feelings and actions, but...they work up and work to this or that identity, for themselves and others." This study certainly further confirms their contention.

\section{Appendix}

$\underline{\text { Transcription conventions }}$

[ The point of overlap onset

$=\quad$ Latching

(0.0) Elapsed time in silence by tenths of seconds

: $\quad$ Prolongation of the immediately prior sound; multiple colons indicate a more prolonged

sound

$\uparrow \quad$ A rising intonation

A falling intonation

A continuing intonation

- $\quad$ A cut-off of the previous sound

( ) The transcriber's inability to hear what was said

(word) The transcriber's best guess of what was said, but the accuracy is not assured

${ }^{\circ}$ word ${ }^{\circ} \quad$ Relatively quieter than the surrounding talk

word Some form of stress (voice amplitude) 


\section{$\underline{\text { Abbreviations in interlinear gloss }}$}

$\begin{array}{ll}\text { Cop } & \text { Copula } \\ \text { IP } & \text { Interactional particle } \\ \text { Neg } & \text { Negative form } \\ \text { Nom } & \text { Nominalizer } \\ \text { OB } & \text { Object marker } \\ \text { Pol } & \text { Politeness marker } \\ \text { Prog } & \text { Progressive form } \\ \text { Q } & \text { Question marker } \\ \text { QT } & \text { Quotation marker } \\ \text { SB } & \text { Subject marker } \\ \text { SF } & \text { Speech filler } \\ \text { Tag } & \text { Tag-like expression } \\ \text { TP } & \text { Topic marker }\end{array}$

\section{References}

Antaki, Charles, and Sue Widdicombe (1998) Identity as an achievement and as a tool. In C. Antaki, and Widdicombe (eds.), Identities in Talk. London: Sage, pp. 1-14.

Baxter, Judith (2008) Is it all tough talking at the top?: A post-structuralist analysis of the construction of gendered speaker identities of British business leaders within interview narratives. Gender and Language 2: $197-222$.

Chiles, Tina (2007) The construction of an identity as "mentor" in white collar and academic workplaces: A preliminary analysis. Journal of Pragmatics 39: 730-741.

Clifton, Jonathan, and Dorien Van De Mieroop (2010) "Doing" ethos - A discursive approach to the strategic deployment and negotiation of identities in meetings. Journal of Pragmatics 42: 2449-2461.

Cook, Haruko M. (1996) The use of addressee honorifics in Japanese elementary school classrooms. In N. Akatsuka, S. Iwasaki, and S. Strauss (eds.), Japanese/Korean Linguistics, vol. 5. Stanford, CA: CSLI, pp. $67-81$.

Cook, Haruko M. (2006) Japanese politeness as an interactional achievement: Academic consultation sessions in Japanese universities. Multilingua 25: 269-291.

Cook, Haruko M. (2008) Style shifts in Japanese academic consultations. In K. Jones, and T. Ono (eds.), Style Shifting in Japanese. Amsterdam: John Benjamins Publishing Company, pp. 9-38.

Cook, Haruko M. (2011) Are honorifics polite? Uses of referent honorifics in a Japanese committee meeting. Journal of Pragmatics 43: 3655-3672.

Fukuda, Chie (2006) Resistance against being formulated as cultural other: The case of a Chinese student 
in Japan. Pragmatics 16: 429-456.

Holmes, Janet (2006) Gendered Talk at Work: Constructing Gender Identity through Workplace Discourse. Malden, MA: Blackwell.

Holmes, Janet, and Meredith Marra (2002) Having a laugh at work: How humour contributes to workplace culture. Journal of Pragmatics 34: 1683-1710.

Holmes, Janet, and Meredith Marra (2004) Relational practice in the workplace: Women's talk or gendered discourse? Language in Society 33: 377-398.

Holmes, Janet, and Maria Stubbe (2003) Power and Politeness in the Workplace: A Sociolinguistic Analysis of Talk at Work. London: Longman.

Jacoby, Sally, and Patrick Gonzales (1991) The constitution of expert-novice in scientific discourse. Issues in Applied Linguistics 2: 149-181.

Makino, Seiichi (2002) When does communication turn mentally inward?: A case study of Japanese formal-to-informal switching. In N. Akatsuka, and S. Strauss (eds.), Japanese/Korean Linguistics, vol. 10. Stanford, CA: CSLI, pp. 121-135.

Mills, Sara, and Louise Mullany (2011) Language, Gender and Feminism: Theory, Methodology and Practice. Oxon: Routledge.

Morita, Emi (2002) Stance marking in the collaborative completion of sentence: Final particles as epistemic markers in Japanese. In N. Akatsuka, and S. Strauss (eds.), Japanese/Korean Linguistics, vol. 10. Stanford, CA: CSLI, pp. 220-234.

Mullany, Louise (2007) Gendered Discourse in the Professional Workplace. Basingstoke: Palgrave.

Ochs, Elinor (1993) Constructing social identity: A language socialization perspective. Research on Language and Social Interaction 26: 287-306.

Ochs, Elinor (1996) Linguistic resources for socializing humanity. In J. Gumperz, and S. Levinson (eds.), Rethinking Linguistic Relativity. Cambridge: Cambridge University Press, pp. 407-437.

Ogasawara, Yoko (1998) Office Ladies and Salaried Men: Power, Gender, and Work in Japanese Companies. Berkeley/Los Angeles/London: University of California Press.

Okamoto, Shigeko (2004) Ideology in linguistic practice and analysis: Gender and politeness in Japanese revisited. In S. Okamoto, and J.S. Shibamoto Smith (eds.), Japanese Language, Gender, and Ideology: Cultural Models and Real People. New York: Oxford University Press, pp. 38-56.

Okamoto, Shigeko, and Janet S. Shibamoto Smith (2008) Constructing linguistic femininity in contemporary Japan: Scholarly and popular representations. Gender and Language 2: 87-112.

Rees, Charlotte E., and Lynn V. Monrouxe (2010) "I should be lucky ha ha ha ha": The construction of power, identity and gender through laughter within medical workplace learning encounters. Journal of Pragmatics 42: 3384-3399.

Schnurr, Stephanie (2009) Constructing leader identities through teasing at work. Journal of Pragmatics 41: 1125-1138.

Spencer-Oatey, Helen (2000) Rapport management: A framework for analysis. In H. Spencer-Oatey (ed.), Culturally Speaking: Managing Rapport through Talk across Cultures. London: Continuum, pp. 11-46.

Sunaoshi, Yukako (1994) Mild directives work effectively: Japanese women in command. In M. Bucholtz, A.C. Liang, L.A. Sutton, and C. Hines (eds.), Cultural Performances: Proceedings of the Third Berkeley 
Women and Language Conference. Berkeley, CA: University of California, pp. 678-690.

Takano, Shoji (2005) Re-examining linguistic power: Strategic uses of directives by professional Japanese women in positions of authority and leadership. Journal of Pragmatics 37: 633-666.

Thomas, Jenny (1995) Meaning in Interaction: An Introduction to Pragmatics. London/New York: Longman.

Vickers, Caroline H. (2010) Language competence and the construction of expert-novice in NS-NNS interaction. Journal of Pragmatics 42: 116-138.

Vine, Bernadette (2004) Getting Things Done at Work: The Discourse of Power in Workplace Interaction. Amsterdam/Philadelphia: John Benjamins Publishing Company.

Zimmerman, Don H. (1998) Identity, context and interaction. In C. Antaki, and S. Widdicombe (eds.), Identities in Talk. London: Sage, pp. 87-106.

JUNKO SAITO is a lecturer in the Japanese/Critical Language Program at Temple University, Japan Campus. Her research interests are sociolinguistics and pragmatics, particularly focusing on language and gender and workplace interactions. Her recent publications are available in Journal of Pragmatics.

Address: Japanese Critical Languages, Temple University, Japan Campus, 2-8-12 Minami-Azabu, Minato-ku, Tokyo 106-0047, Japan. E-mail: saitoj@tuj.temple.edu 